\title{
Redox Conversions of 5-Methyl-6-nitro-7-oxo-4,7-dihydro- 1,2,4triazolo[1,5-a]pyrimidinide L-Arginine Monohydrate as a Promising Antiviral Drug
}

\author{
Alexandra Ivoilova ${ }^{1}{ }^{\oplus}$, Ludmila V. Mikhalchenko ${ }^{2}$, Anton Tsmokalyuk ${ }^{1}$, Marina Leonova ${ }^{2}$, Andrey Lalov ${ }^{2}{ }^{(\mathbb{D}}$, \\ Polina Mozharovskaia ${ }^{1}{ }^{1}$, Alisa N. Kozitsina ${ }^{1}$, Alla V. Ivanova ${ }^{1}$ ) and Vladimir L. Rusinov ${ }^{1,3, *}$ \\ 1 Institute of Chemical Technology, Ural Federal University, 19, Mira St, 620002 Ekaterinburg, Russia; \\ shyra-8@mail.ru (A.I.); atsmok@mail.ru (A.T.); mpnrevda@gmail.com (P.M.); a.n.kozitsina@urfu.ru (A.N.K.); \\ a.v.ivanova@urfu.ru (A.V.I.) \\ 2 Zelinsky Institute of Organic Chemistry, Russian Academy of Sciences, 47, Leninsky Prospect, \\ 119991 Moscow, Russia; mlv@ioc.ac.ru (L.V.M.); marina1235052@gmail.com (M.L.); land@ioc.ac.ru (A.L.) \\ 3 Institute of Organic Synthesis, Ural Branch, Russian Academy of Sciences, 22 Sofia Kovalevsky St, \\ 620137 Ekaterinburg, Russia \\ * Correspondence: v.l.rusinov@urfu.ru
}

check for updates

Citation: Ivoilova, A.; Mikhalchenko, L.V.; Tsmokalyuk, A.; Leonova, M.; Lalov, A.; Mozharovskaia, P.; Kozitsina, A.N.; Ivanova, A.V.; Rusinov, V.L. Redox Conversions of 5-Methyl-6-nitro-7-oxo-4,7-dihydro1,2,4triazolo[1,5-a]pyrimidinide L-Arginine Monohydrate as a Promising Antiviral Drug. Molecules 2021, 26, 5087. https://doi.org/ $10.3390 /$ molecules 26165087

Academic Editor: Alexander V. Aksenov

Received: 15 July 2021

Accepted: 18 August 2021

Published: 22 August 2021

Publisher's Note: MDPI stays neutral with regard to jurisdictional claims in published maps and institutional affiliations.

Copyright: (c) 2021 by the authors Licensee MDPI, Basel, Switzerland. This article is an open access article distributed under the terms and conditions of the Creative Commons Attribution (CC BY) license (https:// creativecommons.org/licenses/by/ $4.0 /)$.

\begin{abstract}
This article presents the results of a study of electrochemical transformations in aqueous and aprotic media of 5-methyl-6-nitro-7-oxo-4,7-dihydro-1,2,4-triazolo[1,5-a]pyrimidinide 1-arginine monohydrate (1a, Triazid) obtained by electrochemical methods and ESR spectroscopy. The effect of $\mathrm{pH}$ on the current and the reduction potential of $\mathbf{1 a}$ in an aqueous Britton-Robinson buffer solution was studied. It was found that $1 \mathrm{a}$ is irreversibly reduced in aqueous acidic media on a glassy carbon electrode in one stage with the participation of six electrons and the formation of 5-methyl-6amino-7-oxo-1,2,4-triazolo[1,5-a]pyrimidin. The electroreduction of 1a in DMF on a background of tetrabutylammonium salts proceeds in two stages, controlled by the kinetics of second-order reactions. In the first stage, the reduction of $\mathbf{1 a}$ is accompanied by protonation by the initial compound of the basic intermediate products formed in the electrode reaction (self-protonation mechanism). The second quasi-reversible stage of the electroreduction 1a corresponds to the formation of a dianion radical upon the reduction of the heterocyclic anion 5-methyl-6-nitro-7-oxo-4,7-dihydro-1,2,4triazolo[1,5-a]pyrimidin, which is formed upon the potentials of the first peak. The ESR spectrum of the radical dianion was recorded upon electroreduction of Triazid in the presence of $\mathrm{Bu}_{4} \mathrm{NOH}$. The effect of the formation of ion pairs on the reversibility of the second peak of the 1a transformation is shown. A change in the rate and regioselectivity of the protonation of the dianion radical in the presence of $\mathrm{Na}^{+}$and $\mathrm{Li}^{+}$ions is assumed. The results of studying the electroreduction of $\mathbf{1 a}$ by ESR spectroscopy with a TEMPO trap make it possible to assume the simultaneous formation of both a nitroxyl radical and a radical with the spin density localized on the nitrogen at the 4 position of the six-membered ring.
\end{abstract}

Keywords: nitro-1,2,4-triazolo[1,5a]pyrimidines; Triazid; nitro group transformations; nitroaromatic compounds; nitroheterocyclic compounds; antiviral drugs; cyclic voltammetry; ESR spectroscopy

\section{Introduction}

It is known that influenza viruses, because of their mutation, are one of the most common and widely spread illnesses. This leads to some difficulties in dealing with influenza. In this regard, the creation of new, more active, and safe medicinal antiviral drugs does not lose its relevance [1-4].

Currently, there is a certain pharmacological niche of drugs based on nitro compounds that are effective against various types of influenza. In recent decades, nitro compounds of an aromatic and heterocyclic nature have attracted considerable attention since they are 
widely used throughout the world as antimicrobial, antiviral, antiparasitic, and radiosensitizing agents $[5,6]$. The mechanism of action of nitroheterocyclic therapeutic agents is currently not completely understood. It is known that medicinal substances, especially nitro compounds, undergo redox transformations in the human body. Some authors have described the connection between process reduction of the nitro group and the biological, antiviral action of these compounds [6,7]. Therefore, the research and development of models that can describe the redox transformation of nitro compounds is an important task. The solutions found through this aim will help advance the understanding of the biological action of pharmaceutical preparations in living organisms based on nitro compounds.

In a wide range of synthetic heterocyclic compounds with antiviral action, a significant place is occupied by azoloazines containing a bridging nitrogen atom in the structure of the molecule 1,2,4-triazolo [1,5-a]triazines and 1,2,4-triazolo[1,5-a]pyrimidine. The interest in azoloazines has resulted from the structural similarity they have to nucleic bases [8]. On the basis of nitro-containing azoloazinium compounds, researchers of the Ural Federal University, named after the first President of Russia, B.N. Yeltsin; the I.Ya. Postovsky Institute of Organic Synthesis of the Ural Branch of the Russian Academy of Sciences (IOS UB RAS); and the A.A. Smorodintsev Research Institute of Influenza of the Ministry of Health of Russia have developed a new class of substances-potential drugs with a wide range of antiviral activity [9]. Triazavirin ${ }^{\circledR}$, or riamilovir (sodium salt of 2-methylthio-6nitro-7-oxo-1,2,4-triazolo[5,1-c][1,2,4]triazine, dihydrate), is the first drug based on this class of compounds. In addition, this drug is included in the register of medicines of the Russian Federation. In the course of its clinical use, Triazavirin has been used in the etiotropic therapy of influenza, acute respiratory viral infections $[10,11]$, and tickborne encephalitis [12]. Triazavirin contributes to a reduction in the duration of the main symptoms of these diseases and a significant decrease in the level of the re-isolation of viruses. The drug has been successfully used in COVID-19 hospitals as an etiotropic agent in the treatment of coronavirus infection, as well as a means of drug prevention [13,14].

There are a number of structural analogs of Triazavirin ${ }^{\circledR}$. The most promising compound, as a molecule with higher antiviral activity against various strains of the virus in in vivo systems, is Triazid (5-methyl-6-nitro-7-oxo-4,7-dihydro-1,2,4triazolo[1,5a]pyrimidinide monohydrate) $[15,16]$. Triazid has passed the first phase of clinical trials, which showed safety, good tolerance, and rapid absorption of the drug [15]. All these results indicate that Triazid is a promising drug to promote on the pharmaceutical market. In this regard, the question of studying its redox transformations is currently of interest.

The electrochemical behavior of monoheterocyclic nitro compounds, for example, pyridine, pyrazole, or imidazole derivatives, is most often similar to the behavior of aromatic nitro compounds [17]. Apparently, the aromaticity of the system is markedly reduced in a number of condensed heterocyclic structures with a bridging nitrogen atom [18]. In addition, new reaction centers, which have the ability to accept electrons and protons, appear. The reciprocal influence of these centers can be so strong that it can cause a radical change in the reactivity of particles [19]. This is probably why the results of studying the reactivity of particles formed from condensed heterocyclic compounds in electrochemical reactions cannot always fit into the framework of conventional concepts.

We previously studied the reduction of the active substance of Triazavirin ${ }^{\circledR}$ and its derivatives (2-R-6-X-7-oxo-1,2,4-triazolo[5,1-c][1,2,4]triazin) in aqueous solutions and aprotic media by electrochemical methods and ESR spectroscopy [20]. Possible mechanisms of its transformation were proposed, and the obtained results indicated a radical mechanism of electroreduction (ER). Previously, we also showed that the reduction of Triazid occurs with the participation of the nitro group of the drug conjugated with the heterocyclic system. At the same time, possible intermediate and final reaction products of the Triazid compound were not studied, because we considered the electroreduction of the nitro group of Triazid only from the point of view of the analytical determination of its maintenance in aqueous solutions [21]. Therefore, the goal of this work was to study the possible pathways of the redox transformation of the molecule 5-methyl-6-nitro-7-oxo-4,7-dihydro- 
1,2,4-triazolo[1,5-a]pyrimidinide l-arginine monohydrate (Triazid), the comparison of its reactivity with the sodium salt of 2-methylthio-6-nitro-7-oxo-1,2,4-triazolo[5,1-c][1,2,4]triazin, dihydrate (Triazavirin ${ }^{\circledR}$ ), and the identification of possible intermediate products of the electroreduction of Triazid using electrochemical methods and ESR spectroscopy.

\section{Experimental Section}

2.1. Materials and Reagents

5-Methyl-6-nitro-7-oxo-4,7-dihydro-1,2,4-triazolo[1,5-a]pyrimidinide 1-arginine monohydrate (1a, Triazid), sodium salt of 5-methyl-6-nitro-7-oxo-4,7-dihydro-1,2,4-triazolo[1,5a]pyrimidine (1b), sodium salt of 2-methylthio-6-nitro-7-oxo-1,2,4-triazolo-[5,1-c][1,2,4] triazin, dihydrate $\left(\mathbf{2 a}\right.$, Triazavirin $\left.{ }^{\circledR}\right)$, and 2-methylthio-6-nitro-7-oxo-1,2,4-triazolo-[5,1c][1,2,4]triazin (2b) were synthesized at the Department of Organic and Biomolecular Chemistry, Ural Federal University. The structure of the compounds (Scheme 1) was determined using NMR spectroscopy, IR and UV spectroscopy, and elemental analysis [22-24].<smiles>Cc1[nH]c2ncnn2c(=O)c1[N+](=O)[O-]</smiles>

$1 \mathbf{a}$<smiles></smiles>

$1 b$<smiles></smiles>

$2 \mathbf{a}$<smiles></smiles>

$2 b$

Scheme 1. Structural formulas of compounds $\mathbf{1 a}, \mathbf{1} \mathbf{b}, \mathbf{2 a}, \mathbf{2} \mathbf{b}$.

To conduct a study of the electroreduction of substances, aqueous solutions of $0.1 \mathrm{M}$ nitric acid of the puriss grade from the USA manufacturer Sigma-Aldrich ${ }^{\circledR}$, St. Louis and Britton-Robinson (BR) buffers were used. The solutions were prepared in distilled water. Britton-Robinson solutions were prepared by mixing orthophosphoric, acetic, and boric acids and adjusting to the required $\mathrm{pH}$ with sodium hydroxide according to [25]. We used acids and salts of the puriss grade from the Spain Barcelona manufacturer PanReac without additional purification. To prepare solutions, we used deionized water obtained on a DVS-M/1NA (18)-N unit from Mediana-Filter, Moscow,Russia.

To carry out the study in aprotic solutions, acetonitrile of the puriss. spec. grade from the USA manufacturer PanReac was used without additional purification. In addition, DMF and DMSO of the puriss. spec. grade from the USA manufacturer Sigma-Aldrich ${ }^{\circledR}$ with preliminary distillation [26] in the presence of a molecular sieve were used. We used lithium perchlorate and tetrabutylammonium tetrafluoroborate of the puriss. spec. grade from the USA manufacturer Sigma-Aldrich ${ }^{\circledR}$.

To detect the radical, $N$-(1-hydroxy-2,2,6,6-tetramethylpiperidin-4-yl-)-2-methylpropanamide hydrochloride (TMTH) (Novosibirsk Institute of Organic Chemistry, Russia) was 
used as a spin probe $[27,28]$. As a spin trap, 3,3,5,5-tetramethyl-1-pyrroline N-oxide (TEMPO) (Sigma-Aldrich ${ }^{\circledR}$, St. Louis, MI, USA, CAS No. 244007) was used $[29,30]$.

\subsection{Electrochemical Devices and Methods}

Cyclic voltammograms (CVs) and chronoamperograms (CAs) were carried out using a $\mu$ Autolab Type III potentiostat/galvanostat (Metrohm, Switzerland). Glassy carbon disks (Ø 2 and $5 \mathrm{~mm}$ stationary or rotating, respectively) were used as a working electrode. The surface of the working electrode was mechanically cleaned before each measurement. A saturated $\mathrm{Ag} / \mathrm{AgCl} / \mathrm{KCl}$ sat electrode acted as a reference electrode in an aqueous medium, and a graphite electrode was used as the auxiliary electrode (Metrohm, Switzerland). The potentials of the working electrode in aprotic solutions were measured relative to a silver chloride reference electrode with two $\mathrm{Ag} / \mathrm{AgCl} / \mathrm{KClsat} / \mathrm{DMF}$ membranes or a saturated calomel electrode (SCE). The CA was recorded at the potentials of the limiting current of electroreduction of compounds in the time interval of $0<\mathrm{t}<5 \mathrm{~s}$, and the logarithmic analysis of the chronoamperograms was performed in the interval of $1<\mathrm{t}<2 \mathrm{~s}$. The working solutions were purged with argon with a purity of $99.9 \%$ for $15 \mathrm{~min}$ before each measurement. Aqueous buffer solutions of Britton-Robinson (BR) or $0.1 \mathrm{M}$ nitric acid were used as supporting electrolytes. The $\mathrm{pH}$ measurements were carried out on an Expert-pH ion meter (Econiks-Expert, Russia) and an EV-74 universal ion meter.

Each voltammogram was recorded three times. The mean peak current and the confidence interval were calculated $(p=0.95$.)

\subsection{ESR Spectroscopy with Preliminary Electrochemical Generation}

ESR spectra were registered using a Bruker Elexsys E 500 spectrometer (Germany, Rheinstetten) with an ER4122SHQE resonator and Bruker EMX 6/1 (Germany Rheinstetten) spectrometer equipped with ER4102ST rectangular cavity equipped with two electrode convex $\mathrm{Pt} / \mathrm{Pt}$ electrolytic cells controlled by a Zahner IM-6 potentiostat.

The generation of Triazid reduction products with a concentration of $0.01 \mathrm{M}$ was carried out with the addition of a $0.01 \mathrm{M}$ spin probe TMTH over 1/5/10/15 min. After the indicated time intervals, an aliquot of the solution was taken, and the ESR spectrum was recorded. To control the number of probes appearing in the background solution, the products were generated in a similar way and at the same potential without adding Triazid. Aliquots were taken after 1/5/10/15 min of generation, and the ESR spectra were recorded.

Before each experiment, the working solution was purged with argon.

Simultaneous Electrochemical Experiment ESR (SEESR) was used to detect paramagnetic particles during 1a reduction. The spectra of the radical anion were recorded at a potential of $-2 \mathrm{~V}$ in a two-electrode $\mathrm{Pt} / \mathrm{Pt}$ electrochemical cell placed in the resonator of an ESR spectrometer. The half-life of the species detected was less than $0.01 \mathrm{~s}$.

All quantum chemical calculations in the field of ESR were performed by the ORCA [31-33] ver. 5.0.0 program package using a hybrid PBE0 [34] density functional in a triple-zeta basis set with two polarization functions def2-TZVPP [35] and atom-pairwise dispersion correction with the Becke-Johnson damping scheme (D3BJ) [36], and respect to the effects of solvation in the SMD continuum [37] were included in all calculations. TightSCF convergence criteria were applied throughout. Full geometry optimization with TightOpt convergence criteria was carried out to find stationary points on the potential energy surfaces. Numerical harmonic frequency calculations were used to obtain thermodynamic quantities and verify that all stationary points found were local minima. Visualization of molecular orbitals were produced using the Avogadro program [38,39].

ESR spectra were recorded with a TEMPO spin trap $[29,30]$ after preliminary generation of Triazid 1a reduction products with a concentration of $0.1 \mathrm{M}$ in DMSO in a conventional electrochemical cell for $15 \mathrm{~min}$ in the presence of a spin trap. An aliquot of the resulting solution was taken, and the ESR spectrum was recorded. 
The simulation and visualization of the calculated ESR spectra with traps were performed using the EasySpin 5.3 software package [40].

\section{Results and Discussion}

\subsection{Electrochemical Behavior of Compounds $\mathbf{1} \boldsymbol{a}$ and $\mathbf{1 b}$ in Aqueous Media}

Figure 1 shows the $\mathrm{CV}$ of the first stages of the electroreduction of the studied compounds in an aqueous acidic medium.

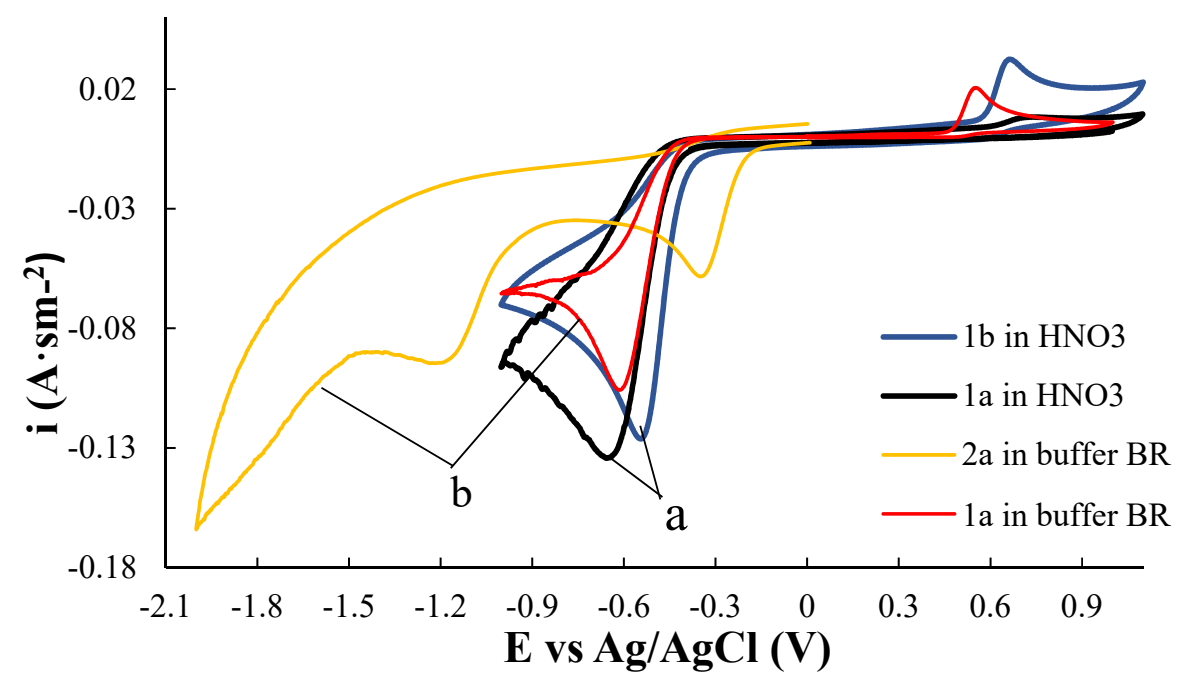

Figure 1. CVs of $5 \mathrm{mM}$ compounds $1 \mathrm{a}$ and $\mathbf{1 b}$ in $0.1 \mathrm{M} \mathrm{HNO}_{3}$ (a) and (2a) and (1a) in a BR buffer solution ( $\mathrm{pH}$ 2) (b) using glassy carbon electrode (GCE). $V=50 \mathrm{mVs}^{-1}$. Potentials were measured relative to $\mathrm{Ag} / \mathrm{AgCl} / \mathrm{KCl}_{\text {sat }}$.

The investigated compounds $1 \mathbf{a}$ and $\mathbf{1 b}$ in $0.1 \mathrm{M} \mathrm{HNO}_{3}$ were irreversibly reduced at the potential values -0.71 and $-0.56 \mathrm{~V}$, respectively. These potentials are comparable to the potentials of heterocyclic nitro compounds with a nitro group in their structure $[6,17,19,41,42]$. The value of the potential of the electroreduction of $\mathbf{1 a}$ in a buffer solution at a $\mathrm{pH}$ of 2 is -0.63 V. Previously, we studied the electroreduction of compound 1a in a buffer solution with a $\mathrm{pH}$ value of 2 [20]. A comparison of the $\mathrm{CV}$ of compounds 1a and 2a showed that under the same conditions $(\mathrm{BR} \mathrm{pH}=2)$, the latter undergoes reduction processes at potential values $250 \mathrm{mV}$ higher than the former. The difference in the ER potentials is probably due to the presence of an additional electronegative nitrogen atom in the six-membered ring of the condensed heterocyclic system 2a. Another difference in the electrochemical behavior of these nitro compounds is the fact that in acidic and neutral media, $\mathbf{2 a}$ is reduced in two subsequent, irreversible stages, while the irreversible peak of the ER of 1a is the only one up to the background discharge potential (Figure S1 Supplementary Materials).

As shown in Figure 1, irreversible peaks of the ER products $\mathbf{1 a}$ and $\mathbf{1} \mathbf{b}$ are observed in nitric acid at potentials +0.68 and $+0.67 \mathrm{~V}$, respectively, on the anodic part of the voltammograms after changing the direction of the potential sweep. The anion of the corresponding hydroxylamino derivative is probably oxidized at these potentials. The closeness of the values of these oxidation potentials indicates the formation of electroreduction products similar in structure to compounds $\mathbf{1 a}$ and $\mathbf{1 b}$.

To determine the effective number of electrons $n_{e}$ involved in the electrochemical reduction reaction, the current of the first stage of the reduction of compound $1 \mathrm{a}$ at a $\mathrm{pH}$ of 2 in the CV was compared with the current calculated using the Rendles-Shevchik equation for irreversible electrochemical reactions [43] and the current of the standard reversible redox system $\mathrm{Fe}(\mathrm{CN})_{6}{ }^{3-} / \mathrm{Fe}(\mathrm{CN})_{6}{ }^{4-}$ under the same conditions (Table 1). In addition, the number of electrons participating in the ER of compound 1a was determined from the value of the limiting current at the rotating disk electrode ( $\left.n_{e} R D E\right)$, the value of the chronoamperogram current at $t=1 \mathrm{~s}\left(\mathrm{n}_{\mathrm{e}} \mathrm{CA}\right)$, and the amount of electricity in the 
interval $t$ from 1 to $2 \mathrm{~s}$, in comparison with the amount of electricity passing under the same conditions at the potential of the limiting recovery current of the model compound $\left(n_{e} C C\right)$. The results are presented in Table 1 , and similar values for $\mathbf{2} \mathbf{a}$ are given for comparison.

Table 1. The values of the observed number of electrons $n_{e}$ involved in the electroreduction of compound $1 \mathbf{a}(C=5 \mathrm{mM})$ in an aqueous buffer solution of $\mathrm{BR}$ at a $\mathrm{pH}$ of 2, determined by CV, CA, CC, and RDE methods.

\begin{tabular}{ccccc}
\hline Compound & $\mathbf{n}_{\mathbf{e}}$ & $\mathbf{n}_{\mathbf{e}}(\mathrm{CA})$ & $\mathbf{n}_{\mathbf{e}}(\mathrm{CC})$ & $\mathbf{n}_{\mathbf{e}}(\mathrm{RDE})$ \\
\hline $\mathbf{1 a}$ & 5.63 & 5.72 & 5.86 & 4.59 \\
$\mathbf{K}_{\mathbf{3}} \mathbf{F e}(\mathrm{CN})_{\mathbf{6}}$ & 1 & 1.02 & 1 & 0.96 \\
$\mathbf{2 a}[20]$ & 3.25 & 4.08 & 4.17 & 3.68 \\
\hline
\end{tabular}

The value of the effective number of electrons $n_{e}$ of the first stage of the electroreduction of compound $2 \mathbf{a}$ was equal to $4 \mathrm{e}$, which suggests the reduction of the nitro group to hydroxylamine [20]. Under the same conditions, the value of $n_{e}$ during the electroreduction of compound 1a is approximately the value 6e. That is, it can be assumed that the intermediate electroreduction products of compound $1 \mathrm{a}$ are electrochemically active at the same potentials, in contrast to the electroreduction products of compound $2 \mathbf{a}$, which are reduced at more negative potentials.

The graph of changes in the limiting current ER of compound $1 \mathrm{a}\left(\mathrm{I}_{\text {lim }}\right)$ at a $\mathrm{pH}$ of 2 on voltammograms obtained at different speeds of rotation of the disk electrode $(\omega)$ in the coordinates $\mathrm{I}_{\text {lim }}$ from $\omega^{0.5}$ is linear but does not pass through the origin of the coordinates (Figure S2 in Supplementary Materials). The current of the ER peak in the CV curves versus $v^{0.5}$ also grows nonlinearly (Figure 2), and the degree of deviation from the straight line depends on the acidity of the medium.

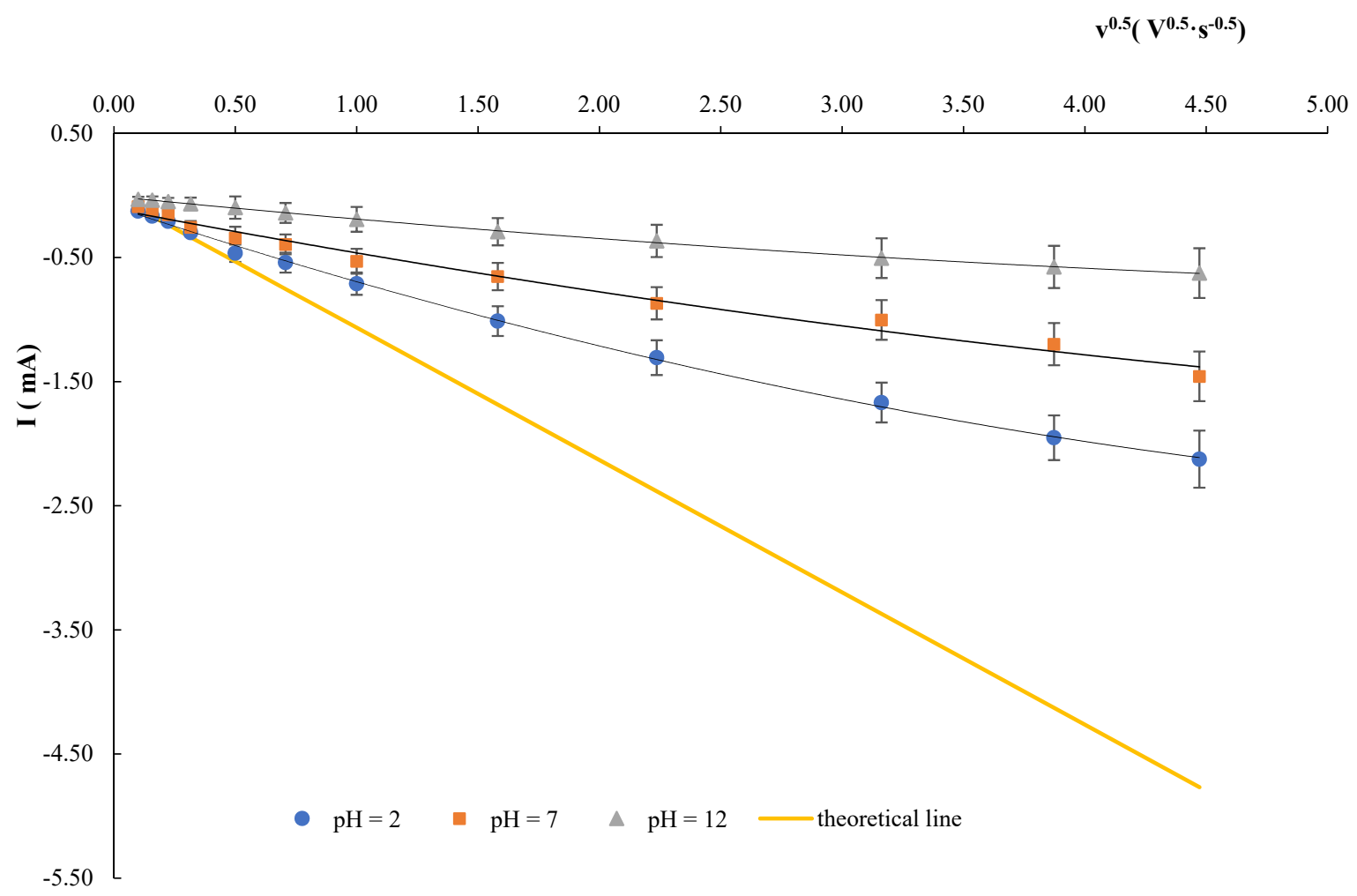

Figure 2. Change in the current of the reduction peak of $5 \mathrm{mM}$ compound 1a from $v^{0.5}$ in the BR buffer solution at a $\mathrm{pH}$ of 2,7 , and 12 and the theoretically calculated current level according to the Rendles-Shevchik equation for irreversible electrochemical reactions $(\mathrm{n}=6 \mathrm{e})$. Potentials were measured relative to $\mathrm{Ag} / \mathrm{AgCl} / \mathrm{KCl}$ sat . 
As shown in Figure 2, the value of the peak current of the ER of 1a deviated from that theoretically calculated by the Rendls-Shevchik equation for irreversible processes [43] at high values of $v \geq 0.75 \mathrm{~V} \cdot \mathrm{s}^{-1}$ in the acidic region. At $\mathrm{pH} 7$, the peak current was close to the theoretically calculated one only at low $v$. The decrease in the peak current for the ER of 1a in alkaline media $(\mathrm{pH}>10)$ at all values of the potential $\mathrm{v}$ is explained [17] by the insufficient protonation rate of the RA due to the low proton concentration. It follows from these data that the electrochemical reaction of the ER of $1 \mathrm{a}$ is controlled by kinetics.

The reduction current in the CV of compound 1a (Figure 3B) in an acidic medium, within the measurement errors, had a maximum current value close to the value of the transfer of $6 \mathrm{e}$ to the $1 \mathrm{a}$ molecule. At a $\mathrm{pH}$ above 4 and in the neutral $\mathrm{pH}$ range, the current gradually decreased. At $\mathrm{pH}$ values of 10-12, the value of current the ER of compound 1a practically did not change and was only approximately $20 \%$ of the maximum value of the ER current of 1a. Such a decrease in the current of the ER of 1a is probably associated with a decrease in the rate of protonation of intermediate anionic species due to the low concentration of protons. However, the electroreduction of compound 1a remained irreversible under these conditions.
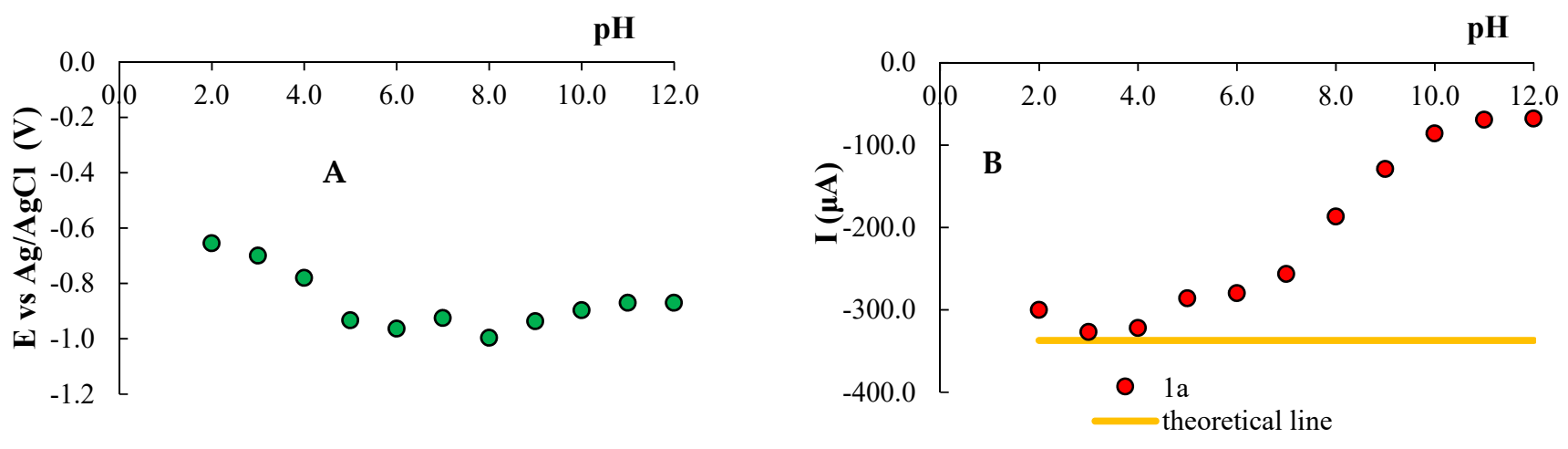

Figure 3. Values of potential (A) and current (B) of the first peak of the ER $5 \mathrm{mM}$ compound of 1a with a change in the $\mathrm{pH}$ of the buffer solution, $v=100 \mathrm{mVs}^{-1}$. Red dots-current calculated by the Rendles-Shevchik equation for irreversible electrochemical reactions involving six electrons. Potentials are measured relative to $\mathrm{Ag} / \mathrm{AgCl} / \mathrm{KCl}$ sat .

With an increase in the $\mathrm{pH}$ of the background electrolyte solution of $3<\mathrm{pH}<6$, the maximum of the reduction peak $1 \mathrm{a}$ shifted toward negative potential values (Figure $3 \mathrm{~A}$ ), with $\Delta \mathrm{E} / \Delta \mathrm{pH}=30 \mathrm{mV}$, and at a $\mathrm{pH}>6$, it remained almost unchanged.

Preparative electrolysis of compound 1a was carried out in an acidic medium (for electrolysis conditions of 1a, see Supplementary Materials). The obtained data from the electrochemical studies of both NMR and mass spectroscopy (Figures S3 and S4 in Supplementary Materials) suggest that the ER of $\mathbf{1 a}$ in aqueous acidic media proceeds at the nitro group of the compound with the participation of 6 electrons per molecule and leads to the formation of the corresponding heterocyclic amine:

${ }^{-} \mathrm{HetNO} \mathrm{NH}_{3}{ }^{+}-\mathrm{R}-\mathrm{COOH}+6 \mathrm{e}+6 \mathrm{H}^{+} \rightarrow \mathrm{HHetNH}_{2}+\mathrm{NH}_{3}{ }^{+}-\mathrm{R}_{-} \mathrm{COO}^{-}+2 \mathrm{H}_{2} \mathrm{O}$

The end product of electroreduction, 5-Methyl-6-amino-7-oxo-4,7-dihydro-1,2,4-triazolo [1,5-a]pyrimidine, was isolated at a yield of $82 \%$ after electrolysis of the solution of $\mathbf{1 a}$ in a BR buffer solution at a $\mathrm{pH}$ of 2 .

The product was obtained as a precipitate upon cooling the catholyte and was not associated with 1-arginine (Figures S3 and S4 in Supplementary Materials).

It is known $[19,44,45]$ that in some cases, when an organic solvent is added to aqueous buffer solutions, the six-electron peak of the nitro group reduction can be divided into two stages. In the CV data of compound 1a, two stages of electroreduction were observed $(5 \mathrm{mM})$ when $40 \%$ DMF was added to the Britton-Robinson buffer solution in the range of $9>\mathrm{pH}>12$, but both stages remained irreversible. In acidic and neutral media, the addition of $40 \%$ DMF or more did not lead to a separation of the ER peak of compound 1a (Figure S5 in Supplementary Materials) These results indicate a high rate of protonation of the formed 
intermediate particles, which results in the formation of compounds electrochemically active at these potentials.

A comparison of the $\mathrm{CV}$ data for compounds $\mathbf{1} \mathbf{a}$ and $\mathbf{1} \mathbf{b}$ (Figure 1) indicated another interesting detail: the currents of the ER of $\mathbf{1 a}$ and $\mathbf{1 b}$ were practically equal, while the ER potentials of these compounds in $0.1 \mathrm{M} \mathrm{HNO}_{3}$ differed noticeably by approximately $150 \mathrm{mV}$. However, it would seem that because both compounds were in an acidic medium, they should be protonated and reduced in the same protonated form. The difference in ER potentials is probably determined by the influence of counterions. The formation of ion pairs of alkali metal ions and small organic cations with anionic particles has been the subject of previous studies $[46,47]$. They showed that the formation of ion pairs leads to a change in the distribution of electron density in the radical anion (RA), which affects the reduction potential of compounds. The difference in the ER potentials of compounds 1a and $\mathbf{~} \mathbf{b}$ is probably related to the effect of $\mathrm{Na}^{+}$ions; $5 \mathrm{mM} \mathrm{Na}^{+}$is added to the solution together with $\mathbf{1 b}$, and in the case of the ER of $1 \mathbf{a}$, the bulky amino acid cation should have little effect on the electron density distribution in RA 1a. In a BR solution at a $\mathrm{pH}$ of 2, a slight decrease in the peak current and a slight shift in the potential of the ER of 1a to the positive region $(-0.63 \mathrm{~V})$ compared with the $\mathrm{HNO}_{3}$ solution are possibly related to the presence of $\mathrm{Na}^{+}$ions.

\subsection{Electroreduction of Compound 1a in Aprotic Media}

In an aprotic medium, anionic intermediate particles formed during reduction are protonated more slowly than they are in an aqueous medium. Therefore, a study of 1a in DMF and acetonitrile was carried out with the aim of registering intermediate electroreduction particles. The electrochemical behavior of $\mathbf{1 a}$ in aprotic solvents was found to be similar. In the CV results 1a in DMF, two ER peaks were observed (Figure 4). The first of them was an irreversible flat ER peak at $-1.22 \mathrm{~V}$, with the next stage at $-1.63 \mathrm{~V}$.

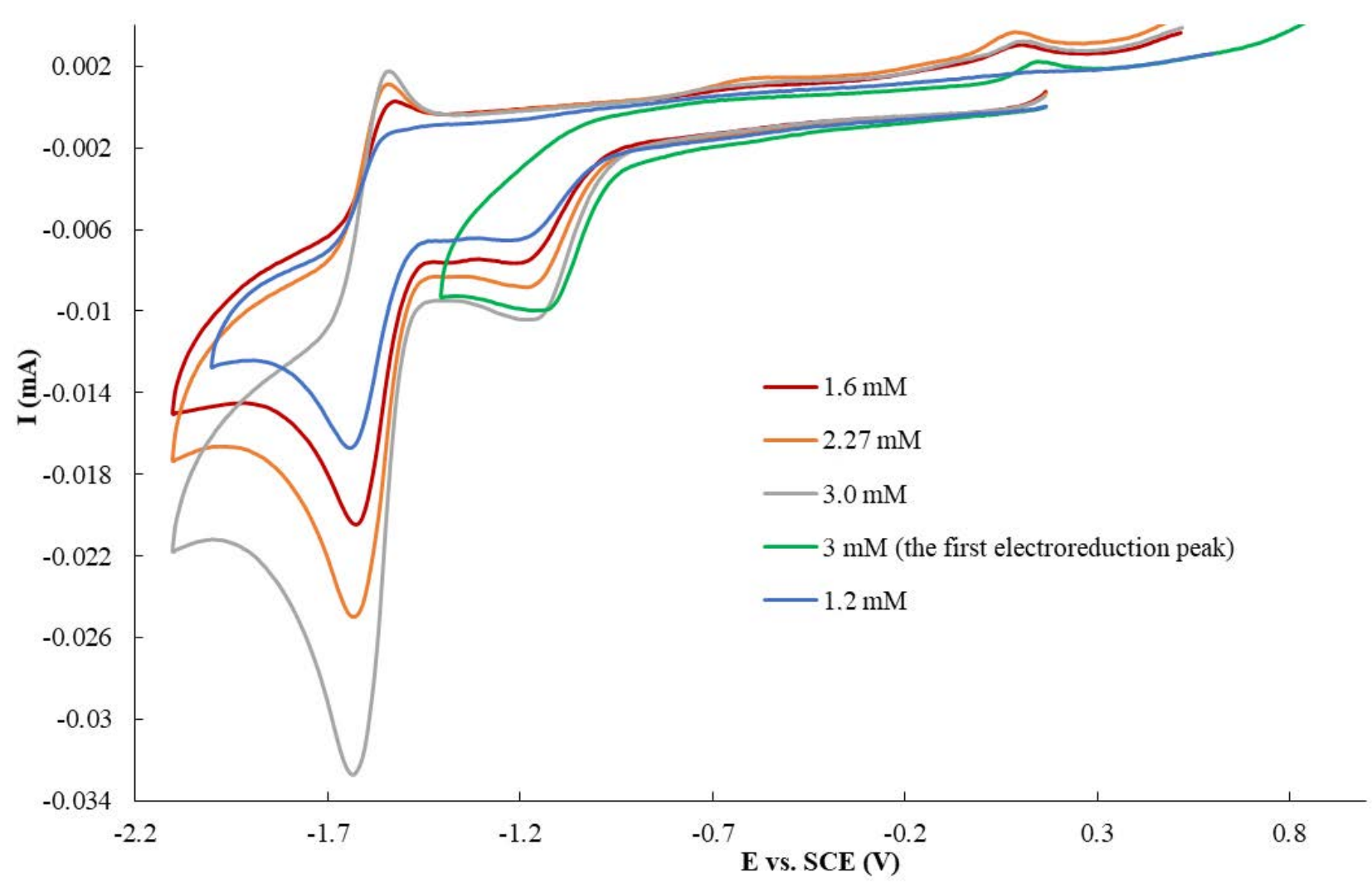

Figure 4. CVs obtained in the presence of compound 1a at various concentrations, 1.2, 1.6, 2.3, and 3.0 mM, in a DMF solution $\left(0.1 \mathrm{M} \mathrm{Bu}_{4} \mathrm{NClO}_{4}\right) . v=100 \mathrm{mVs}^{-1}$. 
According to the CV and CA data, the current value of the first stage of the ER of 1a was noticeably lower than the current of the peak of the one-electron oxidation of ferrocene under the same conditions and varied nonlinearly in the concentration range of 0.6 to $8 \mathrm{mM}$ (Figure 5A). In the range of working concentrations of $1-3 \mathrm{mM}$, the current of the first peak is was approximately half the current of a one-electron transfer.
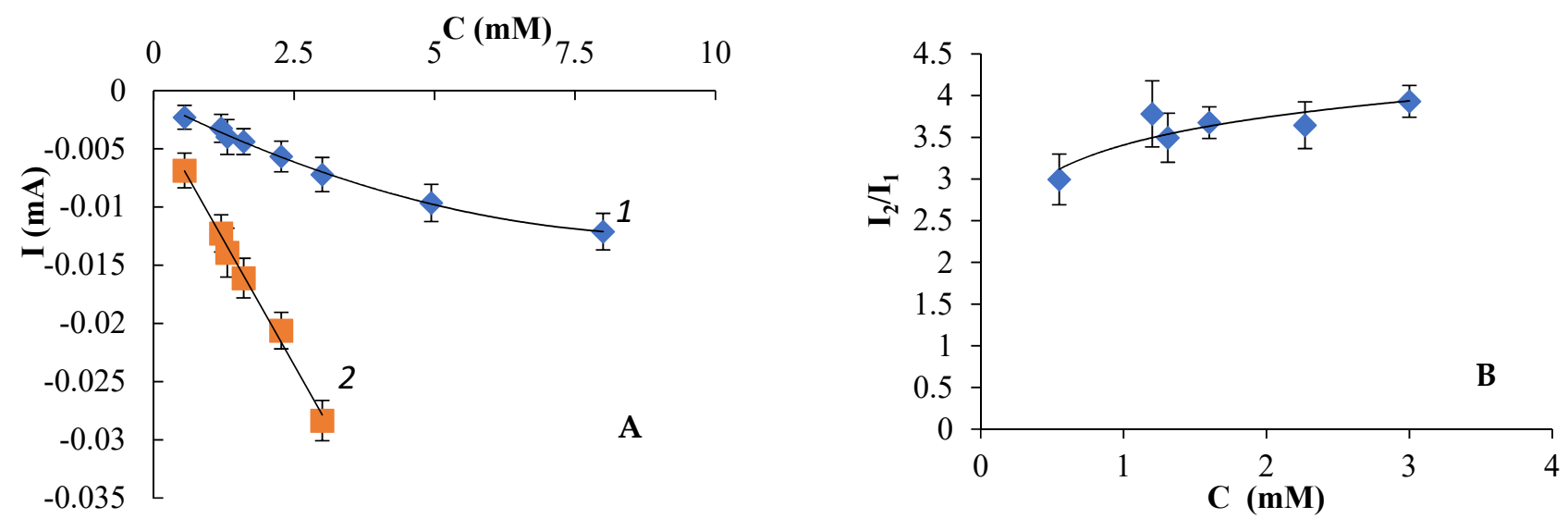

Figure 5. (A) The values of the current on the CVA of compound 1a at the potentials of the first (1) and second (2) stages versus concentration. (B) Change in the ratio of currents at the potentials of the second and first stages $\left(I_{2} / I_{1}\right)$ from the concentration of 1a. $v=100 \mathrm{mVs}^{-1}$.

As shown by the results of the $\mathrm{CV}$ of l-arginine hydrochloride, neither the l-arginine cation nor its anion obtained by adding alkali were not reduced under these conditions. No paramagnetic activity was recorded in l-arginine solutions when the potential was applied under CV conditions. This indicates that, most likely, an electron is transferred to the heterocyclic part of salt 1a. According to the results of quantum-chemical calculations of the energies of the lowest vacant molecular orbital of the heterocyclic anion (LUMO) and the energy of the single-occupied molecular orbital (SOMO) of the dianion radical (DAR) formed during its ER (Figure 6), the most likely explanation that the transfer of electrons to the nitro group and a double bond of a six-membered ring.

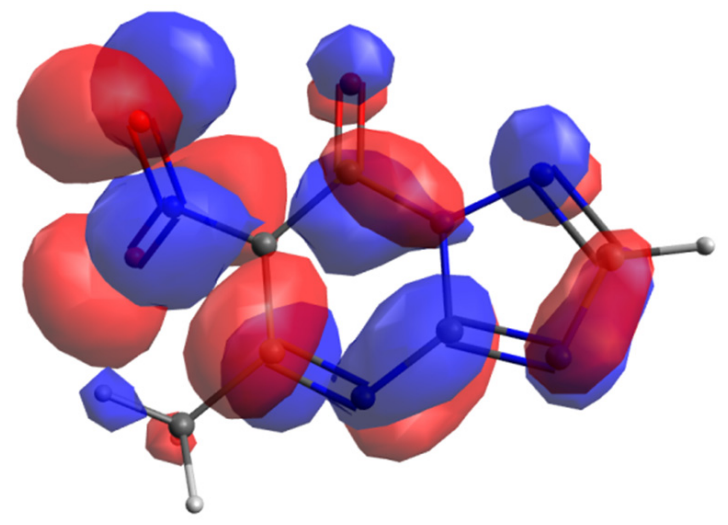

(A)

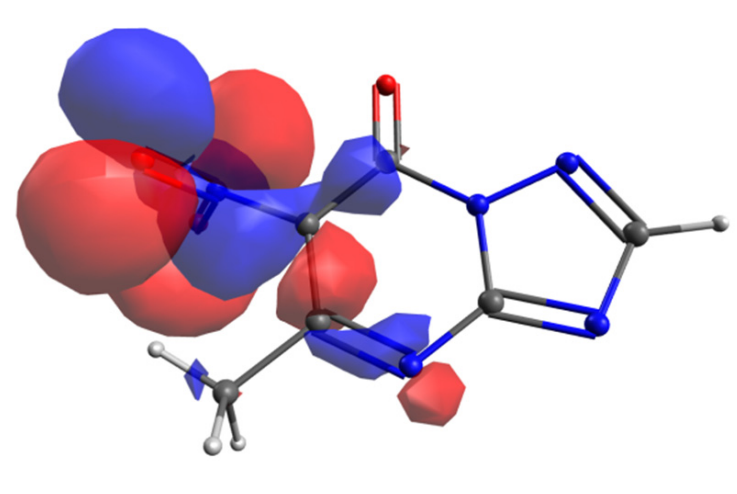

(B)

Figure 6. Orbital plot of the LUMO (A) of heterocyclic anion 1a and the SOMO (B) and its DAR (from PBE0/D3BJ/def2TZVPP calculations).

Since 1a is a salt formed by a heterocyclic anion and an amino acid, it can be assumed that the transfer of the first electron at the potentials of the first stage is accompanied by rapid protonation of the formed ER product by the initial depolarizer-so-called selfprotonation $[48,49]$. The amino acid 1-arginine, which is part of compound $\mathbf{1 a}$, is a good 
proton donor. The pKa value of the first stage in the aqueous medium is 2.17 [50]. The pKa value of compound 1a in water was determined potentiometrically to be 3.45 . Therefore, in an aprotic medium, 1a can act as a proton donor.

The dependence of the current of the first peak $\mathrm{I}_{1}$ of the reduction of $1 \mathrm{a}$ on $v^{0.5}$ in an aprotic medium (Figure 7) is linear and passes through the origin only in the region of low rates of potential application $<2 \mathrm{Vs}^{-1}$.

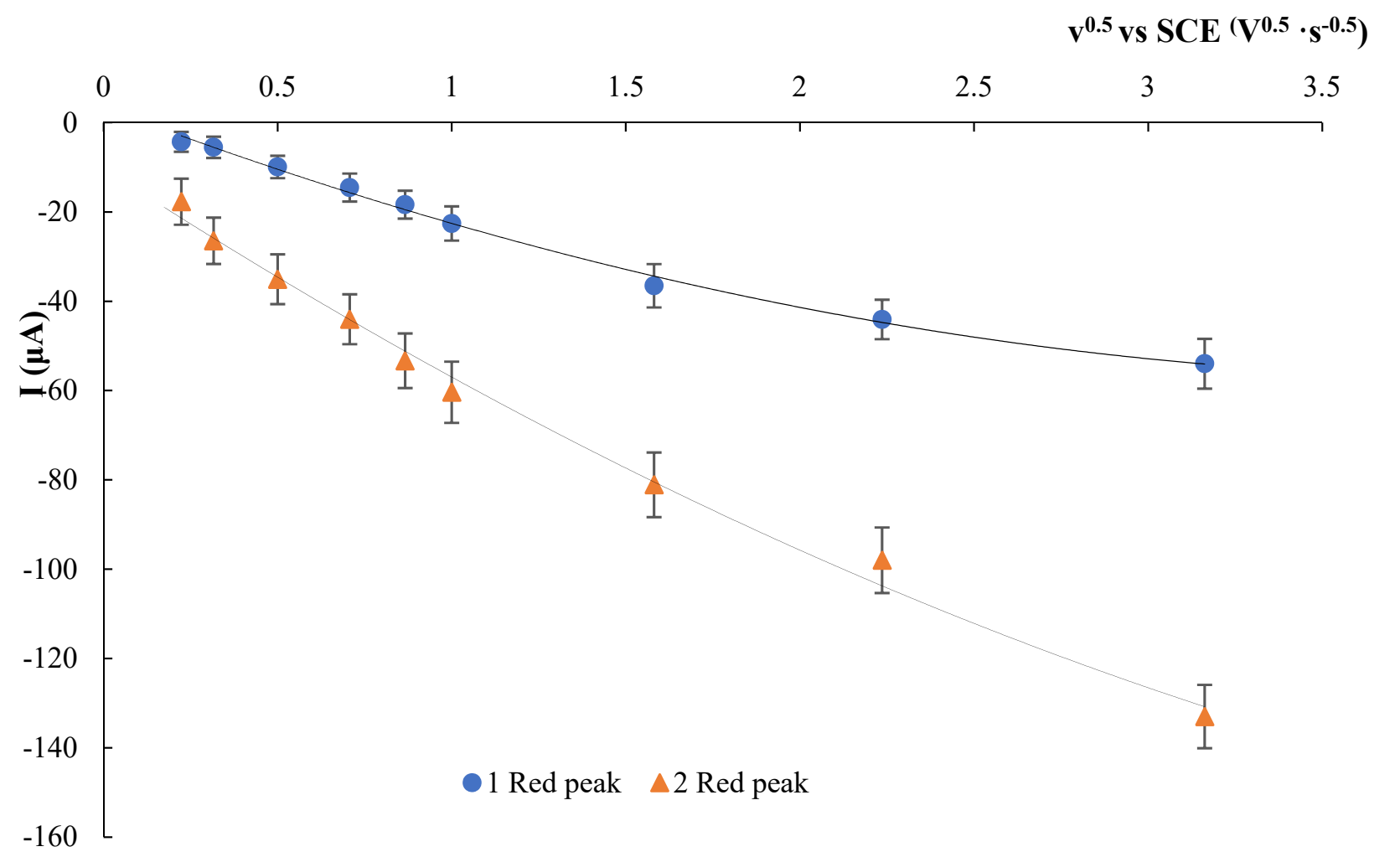

Figure 7. Change in the current of the reduction peaks for $3 \mathrm{mM}$ compound 1a from $v^{0.5}$ in DMF $\left(0.1 \mathrm{M} \mathrm{Bu}_{4} \mathrm{NBF}_{4}\right)$.

The obtained data allow us to assume that at the potentials of the first stage, $E_{1}$, the most rapid reaction is self-protonation leading to the formation of an electrochemically inactive heterocyclic anion $\mathrm{Het}^{-}$at $\mathrm{E}_{1}$ :

$\mathrm{Het}^{-} \mathrm{NH}_{3}{ }^{+}-\mathrm{R}-\mathrm{COOH}+\mathrm{e} \rightarrow\left[\mathrm{Het}^{-} \mathrm{NH}_{3}{ }^{+}-\mathrm{R}-\mathrm{COOH}\right]^{-} E_{1}$

$\left[\mathrm{Het}^{-} \mathrm{NH}_{3}{ }^{+}-\mathrm{R}-\mathrm{COOH}\right]^{-}+\mathrm{Het}^{-} \mathrm{NH}_{3}{ }^{+}-\mathrm{R}-\mathrm{COOH} \rightarrow\left[\mathrm{Het}^{-} \mathrm{NH}_{3}{ }^{+}-\mathrm{R}-\mathrm{COOH}\right] \mathrm{H}+\mathrm{Het}^{-}$ $+\mathrm{NH}_{3}{ }^{+}-\mathrm{R}-\mathrm{COO}^{-}$

Proton transfer can probably proceed not only intermolecularly, but also intramolecularly, as well as through several reaction centers. As a result, the formation of radicals with different positions of the spin density of the unpaired electron and, consequently, different reactivity is possible (Supplementary Materials Scheme S1).

The second stage of the electroreduction of compound 1a is quasi-reversible. On the reverse curve after the second peak in the concentration range of $1.6-3.0 \mathrm{mM}$, an anodic peak was recorded at $\mathrm{E}=-1.54 \mathrm{~V}$ and $\Delta \mathrm{Ep}$ was approximately $90 \mathrm{mV}$. The value of the current at the potentials of the second stage of the ER $\mathrm{I}_{2}$ increased with increasing concentration (Figure 5A), but the linear plot of the dependence of $I_{2}$ in the $C_{1 a} 0.6-3.0 \mathrm{mM}$ interval does not pass through the origin. With an increase in the concentration of $1 \mathrm{a}$, the ratio of the currents at the potentials of the second $I_{2}$ and the first $I_{1}$ stages $I_{2} / I_{1}$ also increased (Figure 5B), which suggests reduction at the potentials of the second stage of the second-order chemical reaction product. The potentials of the second peak, mainly the heterocyclic anion formed at the potentials of the first stage of the ER of $\mathbf{1 a}$, are probably reduced. 
Het $^{-}+\mathrm{e} \rightarrow[$ Het $]=E_{2}$

The oxidation peak of the dianion radical (DAR) on the reverse at a potential of $-1.54 \mathrm{~V}$ was approximately half of the second cathodic peak at $v=0.1 \mathrm{Vs}^{-1}$ (Figure 4), and with an increase in $v$ to $5 \mathrm{Vs}^{-1}$, the value of $\mathrm{I}_{\mathrm{a}} / \mathrm{I}_{\mathrm{c}}$ increased to 0.74 .

The peak current of the second stage of electroreduction of compound 1a from $v^{0.5}$ in an aprotic medium changed nonlinearly (Figure 7). An increase in the $\mathrm{v}$ led to a relative decrease in the currents of both cathodic peaks. Moreover, the $\mathrm{I}_{2} / \mathrm{I}_{1}$ ratio at a high $\mathrm{v}$ (above $2 \mathrm{Vs}^{-1}$ ) remained constant and approximately equal to 2, while at $v=50 \mathrm{mV} \mathrm{s}^{-1}$, it exceeded 4. It can be assumed that the protonation reaction of DAR (with the initial compound and/or donor impurities in the solution) has time to proceed at low values $v$, which leads to an increase in the second cathodic peak and a decrease in the anodic peak at $-1.54 \mathrm{~V}$ in the $\mathrm{CV}$ of compound $\mathbf{1 a}$.

The gradual addition of $\mathrm{Bu}_{4} \mathrm{NOH}$ alkali caused a decrease and complete disappearance of the current of the first stage (Figure 8A) at an equivalent alkali content, while the current value of the second stage remained practically unchanged.
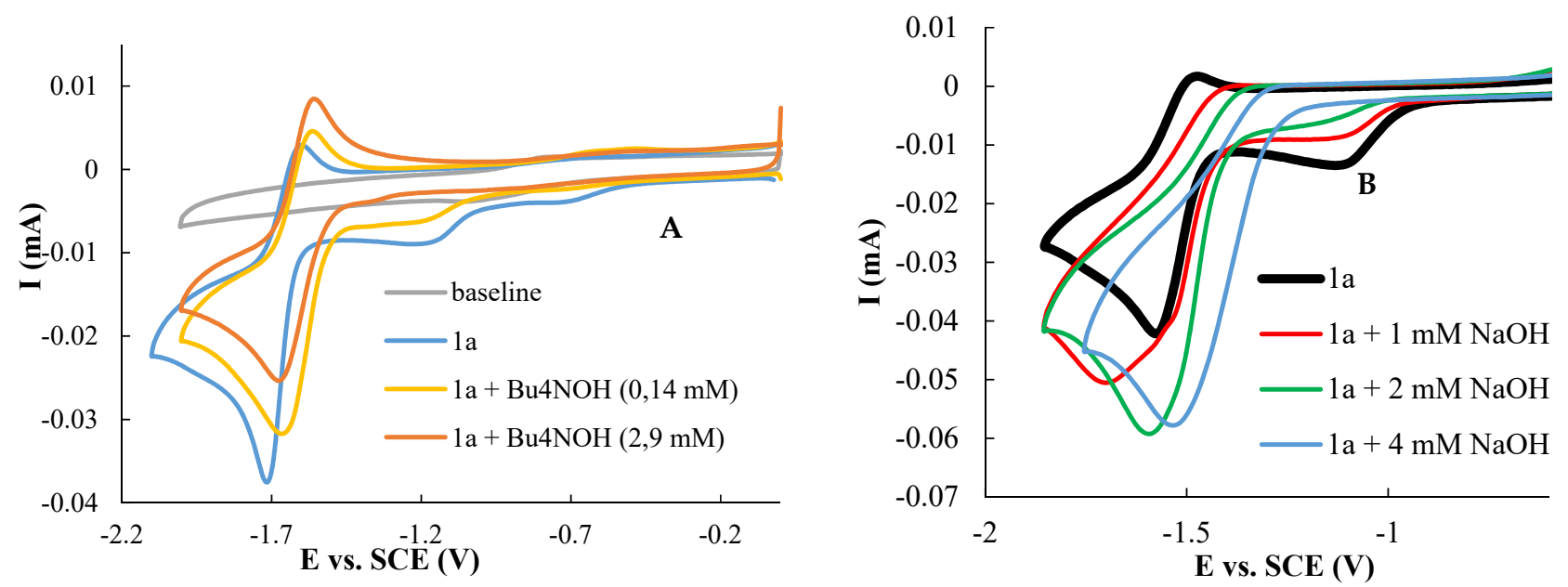

Figure 8. (A) CVs obtained in the presence of compound $1 \mathrm{a}(3 \mathrm{mM})$ in a solution of DMF $\left(0.1 \mathrm{M} \mathrm{Bu}_{4} \mathrm{NBF}_{4}\right) v=0.1 \mathrm{Vs}^{-1}$ with the addition of an aqueous solution of $\mathrm{Bu}_{4} \mathrm{NOH}$. (B) CVs obtained in the presence of compound $1 \mathrm{a}(3.3 \mathrm{mM})$ in a DMF solution $\left(0.1 \mathrm{M} \mathrm{Bu}_{4} \mathrm{NClO}_{4}\right) v=0.1 \mathrm{Vs}^{-1}$ with the addition of an aqueous solution of $\mathrm{NaOH}$.

It is interesting to note that the anodic peak of $-1.54 \mathrm{~V}$ increased under these conditions, and the $\mathrm{I}_{\mathrm{a}} / \mathrm{I}_{\mathrm{c}}$ value was 0.7 when the $\mathrm{Bu}_{4} \mathrm{NOH}$ content was two times higher than the $1 \mathrm{a}$ concentration. This result can be considered a confirmation of the assumption that the DAR formed at the potentials of the second stage of the ER of compound 1a disappears as a result of the protonation reaction. An increase in the rate of potential deposition or a decrease in the content of proton donors due to the addition of alkali makes it possible to register a higher current of its oxidation at a potential of $-1.54 \mathrm{~V}$ :

$\mathrm{Het}^{-} \mathrm{NH}_{3}{ }^{+}-\mathrm{R}-\mathrm{COOH}+\mathrm{OH}^{-} \rightarrow \mathrm{Het}^{-}+\mathrm{NH}_{3}{ }^{+}-\mathrm{R}-\mathrm{COO}^{-}+\mathrm{H}_{2} \mathrm{O}$

$\mathrm{Het}^{-}+\mathrm{e} \rightarrow[$ Het $]=$

The formation of dianion radicals was also shown for a number of 1,2,4-nitrotriazoles [51].

It is important to note that the addition of an aqueous $\mathrm{NaOH}$ solution to a solution of 1a had a different effect on the cathodic peaks of the CVs of the compound (Figure 8B). The addition of $\mathrm{NaOH}$ to a solution of $1 \mathbf{a}$ in DMF also led to the disappearance of the first stage of the ER. The second stage became irreversible, while the potential of the ER shifted to more positive potentials, and the current increased. Apparently, these changes can be associated with the formation of ion pairs between the heterocyclic anion $1 \mathrm{a}$ and $\mathrm{Na}^{+}$ions, in which the electron density at the reaction center increases under the influence of the cation, and the protonation of DAR proceeds at a higher rate. When $\mathrm{Bu}_{4} \mathrm{NOH}$ was added to the solution instead of $\mathrm{NaOH}$ (Figure 8A), ion pairs with the heterocyclic anion were not 
formed since the charge density in the bulk cation $\mathrm{Bu}_{4} \mathrm{~N}^{+}$is significantly lower than that in the $\mathrm{Na}^{+}$ion. As a result, the reversible ER of the 1a anion was observed on the CVs.

Figure 9 shows the cyclic voltammograms of the solution of $\mathbf{1 a}$ in the presence of added $\mathrm{LiClO}_{4}$. These were made in order to exclude the effect of the water added with alkali to the DMF solution and to study the effect of a cation even smaller than $\mathrm{Na}^{+}$.

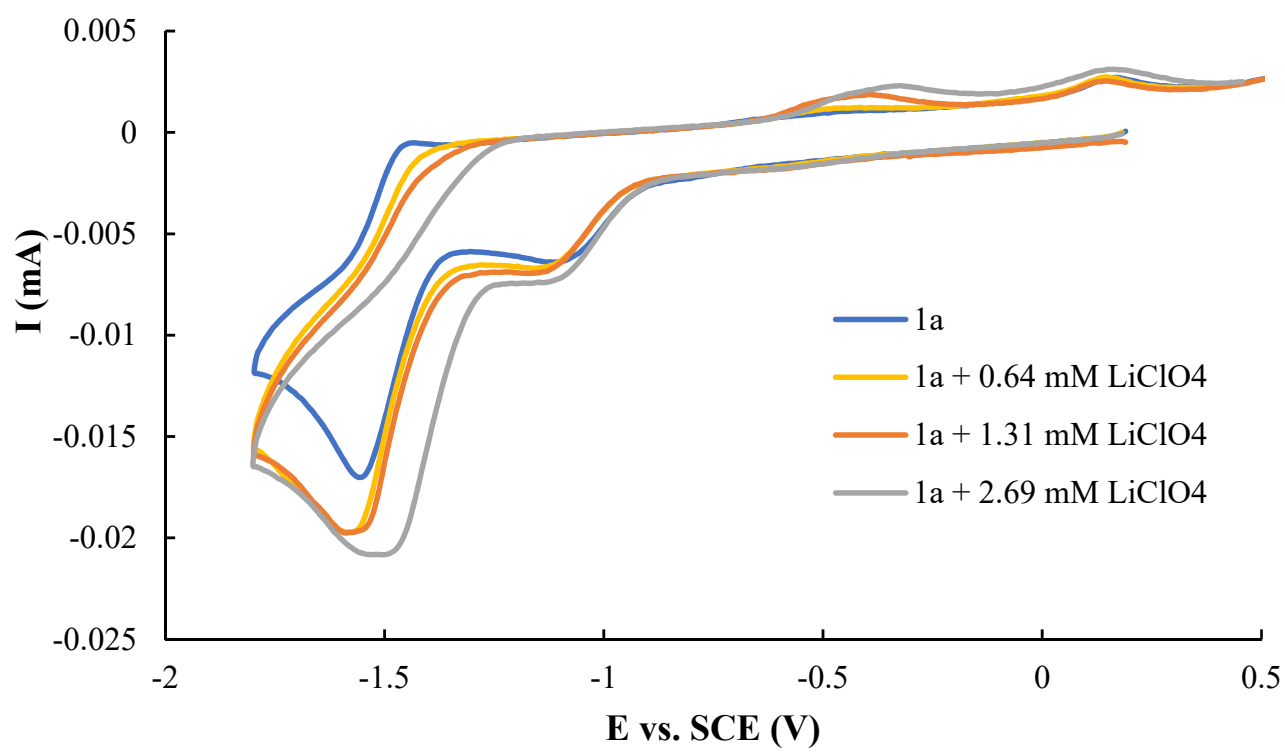

Figure 9. CVs of a $1.3 \mathrm{mM}$ solution of $1 \mathrm{a}$ in the presence of $\mathrm{LiClO}_{4}, v=0.1 \mathrm{Vs}^{-1}$.

By comparing the influences of $\mathrm{LiClO}_{4}$ and $\mathrm{NaOH}$, it can be noted that the presence of $\mathrm{LiClO}_{4}$, in contrast to that of $\mathrm{NaOH}$, does not affect the first stage of the ER of $1 \mathbf{a}$, but the second stage of ER in the presence of both compounds becomes irreversible and the reduction current increases, probably due to the protonation of the resulting products. In addition, in both cases, oxidation peaks appear on the anodic reversal curve at close potentials in the range of -0.5 to $-0.3 \mathrm{~V}$. It is possible that in the presence of alkali metals, not only does the rate of protonation of $\mathbf{1 a}$ dianion radicals change, but the regioselectivity of the chemical reaction also changes. It should be emphasized that the ESR signal could not be detected in the presence of $\mathrm{Li}^{+}$ions when $\mathrm{LiOH}$ was added to a solution of $\mathbf{1 a}$ in DMF.

\subsection{Study of the Products of Electroreduction of Compound 1a by ESR Spectroscopy}

The electron density of the lowest free molecular orbital (LUMO) of the heterocyclic anion 1a was theoretically calculated to determine the possible reduction centers (Figure 6). From these calculations, two possible pathways for the formation of radicals were suggested. The first, which is the most probable, is the reduction of the nitro group with the formation of a nitroxyl radical, and the second is the formation of a radical on the nitrogen at the 4 position of the six-membered ring of the heterocycle.

Preliminary reduction of $1 \mathrm{a}$ was carried out at a peak potential of $\mathrm{E}=-1.7 \mathrm{~V}$ in a DMSO solution in the presence of a TMTH spin probe to detect the formation of radical products during the ER of 1a. The obtained experimental data indicate the appearance of radicals in the solution of the electrochemical cell during electrolysis. A significant increase in the number of paramagnetic centers in the solution of the electrochemical cell during the entire electrolysis process for 1a (Figure S6 in Supplementary Materials) was observed. In addition, a linear relationship between the number of spins and the time spent on the electroreduction of the products of 1a was observed (Figure S6 tab in Supplementary Materials). 
The high reactivity of the anionic particles formed during the ER of 1a, primarily in the protonation reactions, makes it difficult to obtain high-intensity ESR spectra. Therefore, the ER of $1 \mathrm{a} c$ was carried out in an SEESR experiment in the presence of $\mathrm{Bu}_{4} \mathrm{NOH}$.

The SEESR experiment was used for the detection of paramagnetic species during the reduction of 1a. Figure 10 gives examples of the experimental and simulated spectra of the radical anion generation recorded at a potential of $-2 \mathrm{~V}$ in a two-electrode $\mathrm{Pt} / \mathrm{Pt}$ electrochemical cell placed in the resonator of an ESR spectrometer. The half-life of the detected species was less than $0.01 \mathrm{~s}$.
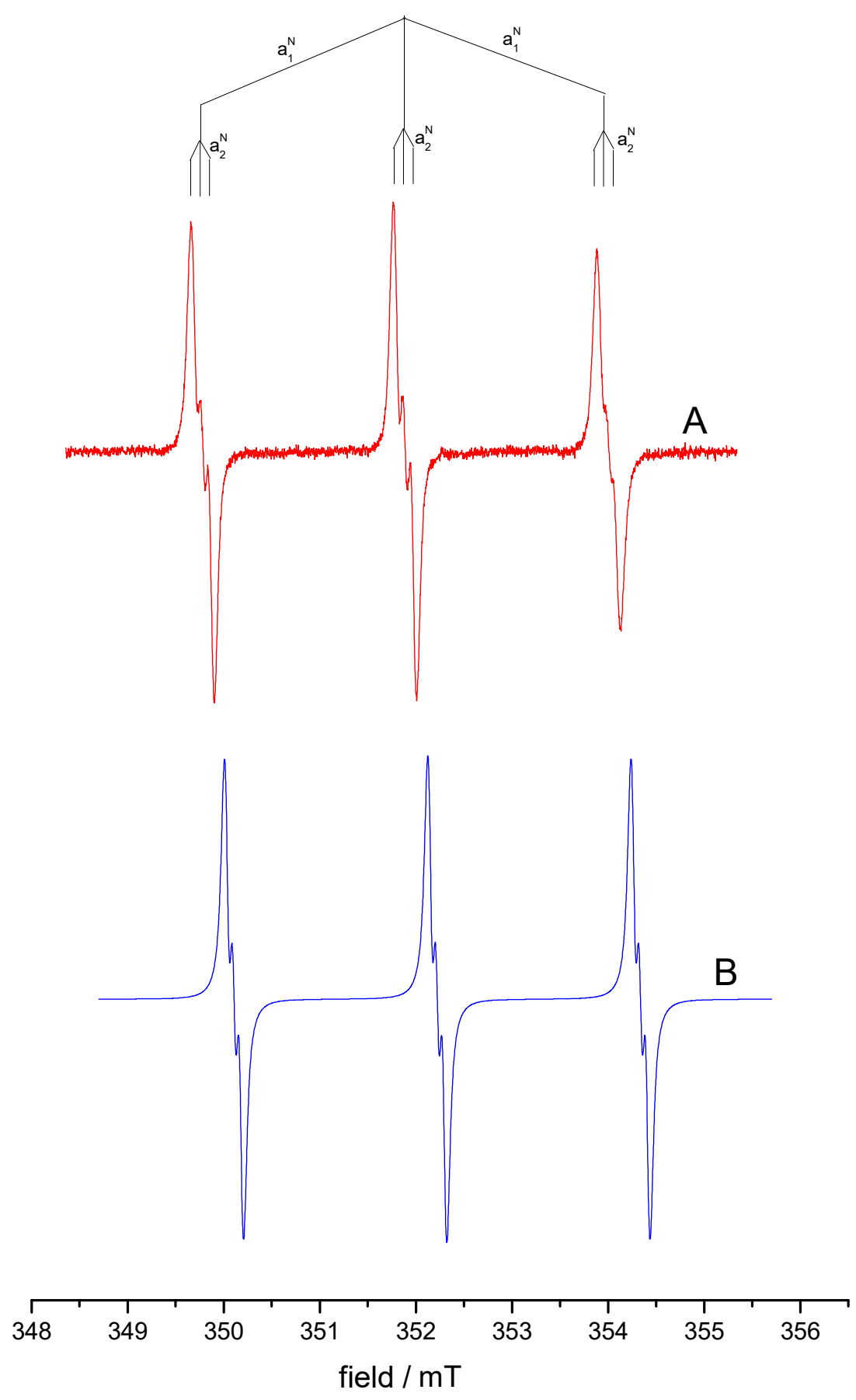

Figure 10. ESR spectra of the radical dianion: experimental (A) (room temperature, $\left.\mathrm{DMF} / \mathrm{Bu}_{4} \mathrm{NClO}_{4} / \mathrm{Bu}_{4} \mathrm{NOH}\right)$ and simulated isotropic spectrum $(\mathrm{B})$ triplet of triplets $\left(\mathrm{g}_{\mathrm{i}}=2.0059, a_{1}^{N}\right.$ $\left.(\operatorname{spin}=1)=2.12 \mathrm{mT}, a_{2}^{N}(\operatorname{spin}=1)=0.7 \mathrm{mT}, \mathrm{LW}=0.065 \mathrm{mT}, \mathrm{L} / \mathrm{G}=0.1\right)$. 
The isotropic spectrum of the radical dianion recorded at room temperature was a triplet of triplets - three equidistant lines by splitting on the nitrogen (spin =1) of the $\mathrm{NO}_{2}$ group $\left(a_{1}^{N}=2.12 \mathrm{mT}\right)$, with each of them split by a small constant $\left(a_{2}^{N}=0.7 \mathrm{mT}\right)$ on the nitrogen (spin $=1$ ) in position 4 of the heterocycle.

Calculated using the DFT level of theory (PBE0/def2-TZVPP), the hyperfine coupling constants for the dianion radical of $1 \mathrm{~A}-\mathrm{g}_{\mathrm{i}}=2.0057, a_{1}^{N}\left(\mathrm{NO}_{2}\right.$ group $)=2.28 \mathrm{mT}$, and $a_{2}^{N}(\mathrm{~N}$ in the 4 position of the heterocycle) $=0.44 \mathrm{mT}$-were in agreement with the experiment.

The ESR spectra of the adducts of the TEMPO spin trap with the reduction product 1a are additional evidence of the structure of the radicals formed during the ER of 1a (Figure S7 in the Supplementary Materials). The obtained ESR spectrum can be described as a superposition of the ESR spectra of two adducts; in one adduct, the center of the interaction of the spin trap with the supposed radical is the nitro group, and in the second, the center is the nitrogen atom in position 4 of the six-membered heterocycle.

\section{Conclusions}

The results of this study of the electrochemical behavior of compound 1a (5-methyl-6nitro-7-oxo-4,7-dihydro-1,2,4-triazolo[1,5-a]pyrimidinide 1-arginine monohydrate) in an acidic aqueous medium showed that the electroreduction of the nitro group of this compound proceeds irreversibly in one six-electron step with the formation of the corresponding heterocyclic amine. The ER of 1a proceeds at more negative potentials in comparison with that of the previously studied $\mathbf{2 a}$ in both aqueous and aprotic media. Compound 1a is reduced in two stages in aprotic media. The transfer of the first electron is accompanied by the competition of protonation reactions with the participation of the starting compound 1a. At the potentials of the second stage, the heterocyclic anion 1a is reversibly reduced to form the dianion radical. The ESR spectrum of this particle was recorded upon the ER of compound $1 \mathrm{a}$ in the presence of $\mathrm{Bu}_{4} \mathrm{NOH}$.

The effect of $\mathrm{Na}^{+}$and $\mathrm{Li}^{+}$ions added to the DMF solution was considered. In the presence of these ions, not only does the rate of protonation of the dianion radicals of the investigated compound change, but the regioselectivity of this reaction also changes. The results of ESR spectroscopy make it possible to assume the formation of both a nitroxyl radical and a radical with spin density localization on nitrogen in the 4 position of the six-membered ring during the ER of 1a. The obtained ESR spectrum of adducts of radical particles with a TEMPO spin trap can be described as a superposition of the ESR spectra of these radicals.

Supplementary Materials: The following are available online. Figure S1: CVs obtained in BR solution and compound 1a before background discharge. Figure S2: The dependence of the limiting current of the electroreduction of compound $1 \mathrm{a}\left(\mathrm{C}=5 \cdot 10^{-3} \mathrm{mM}\right)$ on $\omega^{0.5}$ in a BR solution with $\mathrm{pH}=2$. Figure S3: NMR spectrum of the product after electrolysis of 1a. Figure S4: Mass spectra of products after electrolysis of 1a. Electrolysis of compound 1a in an acidic medium. Figure S5: CVs of $1 \mathrm{a}$ in a $60 \%$ Britton-Robinson buffer with $40 \%$ DMF. Sweep scan $50 \mathrm{mVs}^{-1}: 1-\mathrm{pH}=2$; $2-\mathrm{pH}=9 ; 3-\mathrm{pH}=12$. Scheme S1: Possible further ways of reducing 1a. Figure S6: ESR spectra of the products of the reduction reaction of compound 1a with the TMTH probe and the relative number of paramagnetic centers after $0,1,5,10$, and $15 \mathrm{~min}$ of electroreduction at $-1.7 \mathrm{~V}$. Figure S7: ESR spectra of TMPO spin trap adducts with a reduction product 1a.

Author Contributions: V.L.R. developed the research concept. A.V.I., A.N.K., and L.V.M. designed the study. A.I., L.V.M., and P.M. performed and analyzed the CV electrochemical measurements and drafted and revised the article. A.L. and A.T. performed and analyzed the ESR analysis experiments and calculations. M.L. performed and analyzed the NMR and HRMS measurements. Writingreview and editing, V.L.R., A.N.K., and A.V.I. All authors have read and agreed to the published version of the manuscript.

Funding: This work was supported by the Russian Foundation for Basic Research (RFBR, project No. 19-29-08015 mk).

Institutional Review Board Statement: Not applicable. 
Informed Consent Statement: Not applicable.

Data Availability Statement: The data presented in this study are available on request from the corresponding author.

Conflicts of Interest: The authors declare no conflict of interest.

Sample Availability: Samples of the compounds 5-Methyl-6-nitro-7-oxo-4,7-dihydro-1,2,4-triazolo [1,5-a]pyrimidinide l-arginine monohydrate (1a, Triazid), sodium salt of 5-methyl-6-nitro-7-oxo-4,7dihydro-1,2,4-triazolo[1,5-a]pyrimidine (1b), sodium salt of 2-methylthio-6-nitro-7-oxo-1,2,4-triazolo[5,1-c][1,2,4]triazin, dihydrate (2a, Triazavirin $\left.{ }^{\circledR}\right)$, and 2-methylthio-6-nitro-7-oxo-1,2,4-triazolo-[5,1c] $[1,2,4]$ triazin $(\mathbf{2 b})$ are available from the authors.

\section{References}

1. Nepali, K.; Lee, H.Y.; Liou, J.P. Nitro-Group-Containing Drugs. J. Med. Chem. 2018, 62, 2851-2893. [CrossRef] [PubMed]

2. Rossignol, J.F. Thiazolides: A new class of antiviral drugs. Expert Opin. Drug Metab. Toxicol. 2009, 5, 667-674. [CrossRef] [PubMed]

3. Otsuka and Mylan Announce License Agreement to Commercialize Delamanid (Deltyba ${ }^{\mathrm{TM}}$ ) for Multidrug-Resistant Tuberculosis (MDR-TB) in HighBurden Countries. PR Newswire: News distribution, targeting and monitoring. Available online: https: / / www.prnewswire.com/news-releases / otsuka-and-mylan-announce-license-agreement-to-commercialize-delamaniddeltyba-for-multidrug-resistant-tuberculosis-mdr-tb-in-high-burden-countries-300508333.html (accessed on 24 June 2021).

4. Halsey, J.L. Current Approaches to the Treatment of Gastrointestial Infections: Focus on Nitazoxanide. Clin. Med. Ther. 2009, 1, 263-275. [CrossRef]

5. Kedderis, G.L.; Miwa, G.T. The metabolic activation of nitroheterocyclic therapeutic agents. Drug Metab. Rev. 1988, 19, 33-62. [CrossRef] [PubMed]

6. Wardman, P. Application of pulse radiolysis methods to study the reactions and structure of biomolecules. Rep. Prog. Phys. 1978, 41, 259-296. [CrossRef]

7. Grunberg, E.; Titsworth, E.H. Chemotherapeutic properties of heterocyclic compounds: Monocyclic compounds with fivemembered rings. Annu. Rev. Microbiol. 1973, 27, 317-346. [CrossRef]

8. Robins, R.K.; Revankar, G.R.; O’Brien, D.E.; Springer, R.H.; Albert, T.N.A.; Senga, K.; Miller, J.P.; Streeter, D.G. Purine analog inhibitors of xanthine oxidase-structure activity relationships and proposed binding of the molybdenum cofactor. J. Heterocycl. Chem. 1985, 22, 601-634. [CrossRef]

9. Rusinov, V.L.; Charushin, V.N.; Chupakhin, O.N. Biologically Active Azolo-1,2,4-Triazines and Azolopyrimidines. Russ. Chem. Bull. 2018, 1, 573-599. [CrossRef]

10. Sologub, T.V.; Tokin, I.I.; Midikari, A.S.; Tsvetkov, V.V. A comparative efficacy and safety of using antiviral drugs in therapy of patients with influenza. Infektsionnye Bolezn. 2017, 15, 25-32. [CrossRef]

11. Lioznov, D.A.; Tokin, I.I.; Zubkova, T.G.; Sorokin, P.V.; Zhdanov. Practice of application of domestic anti-viral drug in etiotropic therapy of acute respiratory viral infection. Ter. Arkhiv 2021, 92, 59-63. [CrossRef]

12. Tihonova, E.P.; Yu, T.; Kuzmina, A.A.; Anisimova, Y.; Kalinina, S. Nitrosynthones in the synthesis of nitrodividuals of azolo [1,5-a] pyrimidines and azolo [5,1-c] -1,2,4-triazines. Eksperimentalnaya klynicheskaya Farmacol. 2018, 350, 25-32. [CrossRef]

13. Kasyanenko, K.V.; Kozlov, K.V.; Maltsev, O.V.; Lapikov, I.I.; Gordienko, V.V.; Sharabhanov, V.V.; Sorokin, P.V.; Zhdanov, K.V. Evaluation of the effectiveness of Riamilovir in the complex therapy of patients with COVID-19. Ter. Arkhiv 2021, 93, 291-295. [CrossRef]

14. Sabitov, A.U.; Sorokin, P.V.; Dashutina, S.Y. Experience of the preventive use of the drug Riamilovir in the foci of coronavirus infection (COVID-19). Ter. Arkhiv 2021, 93, 435-439. [CrossRef]

15. Deyeva, E.G.; Shevchik, Y.I.; Shaldghan, A.A.; Zagorodnikova, K.A.; Tumashov, A.A.; Baklykov, A.V.; Kotovskaya, S.K.; Chupahin, O.N.; Charushin, V.N.; Rusinov, V.L.; et al. New antiviral drug TRIAZID. Results of first phase of clinical trial. Razrab. Regist. Lek. Sredstv 2018, 3, 172-180.

16. Slepukhin, P.A.; Voinkov, E.K.; Ulomskiy, E.N.; Savateev, K.V.; Kopchuk, D.S.; Zyryanov, G.V.; Fedotov, V.V.; Charushin, V.N.; Chupakhin, O.N.; Rusinov, V.L. Synthesis and X-ray structural studies of 5-methyl-6-nitro-7-oxo-4,7-dihydro-1,2,4-triazolo[1,5a]pyrimidine L-arginine and piperidine salts. Chem. Heterocycl. Compd. 2019, 55, 989-992. [CrossRef]

17. Baizer, M.M.; Lund, H. Organic Electrochemistry; Lund, H., Ed.; Marcel Dekker: New York, NY, USA, 1983; ISBN 978-042-913-168-4.

18. Kornilov, M.Y.; Turov, A.V.; Myasnikov, A.V.; Torgashev, P.A.; Rusinov, V.L.; Chupakhin, O.N. Aromaticity of nitroazoloazines with a bridging nitrogen atom. Zhurnal Org. Khimii. 1991, 27, 144-148.

19. Zuman, P. Half a century of research using polarography. Microchem. J. 1997, 57, 4-51. [CrossRef]

20. Ivoilova, A.V.; Mikhal'chenko, L.V.; Tsmokalyuk, A.N.; Kozitsina, A.N.; Ivanova, A.V.; Rusinov, V.L. Redox conversions of new antiviral drug Triazavirin ${ }^{\circledR}$ : Electrochemical study and ESR spectroscopy. Russ. Chem. Bull. 2021, 70, 1099-1108. [CrossRef]

21. Malakhova, N.A.; Ivoilova, A.V.; Zamana, A.A.; Rusinov, V.L.; Alyamovskaya, I.S.; Ivanova, A.V.; Kozitsina, A.N. Quantitative Determination of the Main Substance of the Triazid ${ }^{\circledR}$ Antiviral Drug by Voltammetry. J. Anal. Chem. 2020, 75, 396-401. [CrossRef] 
22. Bull, O.N.; Chupakhin, V.N.; Charushin, V.L.; Rusinov, E.N.; Ulomsky, S.K.; Kotovskaya, O.I.; Kiselev, E.G.; Deeva, K.V.; Sa-vateev, S.S. Byul. Izobret 5-methyl-6-nitro-7-oxo-4,7-dihydro-1,2,4-triazolo [1,5-alpha] pyrimidinide l-argininium mono-hydrate. Borisov Patent RF 2529487, 20 October 2014. (In Russian)

23. Bull Kiselev, O.I.; Petrov, A.Y.; Rusinov, V.L.; Ulomskiy, E.N.; Charushin, V.N.; Chupakhin, O.N. Izobret 5-methyl-6-nitro-1,2,4,triazolo[1,5-a]pyrimidin-7-one dihydrate sodium salt. Patent RF 2330036, 27 July 2008. (In Russian)

24. Bull, O.N.; Chupakhin, O.N.; Chupakhin, V.L.; Rusinov, E.N.; Ulomsky, E.N.; Ulomsky, V.N.; Charushin, V.N.; Charushin, A.Y.; Petrov, A.Y.; Petrov, O.I. IzobretSodium salt of 2-methylthio-6-nitro-1,2-4-triazolo[5,1-c]-1,2,4-triazin-7 (4h) -one, dihydrate with antiviral activity. Kiselev Patent RF 2294936, 10 March 2007. (In Russian)

25. Lurie, Y.Y. Handbook of Analytical Chemistry; Chemistry: Moscow, Russia, 1971; ISBN 978-5-903034-26-0.

26. Wilfred, L.F. Purification of Laboratory Chemicals; Perrin, D.D., Ed.; Elsevier: Amsterdam, The Netherlands, 2013; ISBN 0-08-0347142 .

27. Dikalov, S.; Skatchkov, M.; Bassenge, E. Spin Trapping of Superoxide Radicals and Peroxynitriteby 1-Hydroxy-3-carboxypyrrolidine and 1-Hydroxy-2,2,6,6-tetramethyl-4-oxo-piperidine and the Stability ofCorresponding Nitroxyl Radicals Towards BiologicalReductants. Biochem. Biophys. Res. Commun. 1997, 231, 701-704. [CrossRef] [PubMed]

28. Dikalov, S.I.; Kirilyuk, I.A.; Voinov, M.; Grigor'ev, I.A. ESR detection of cellular and mitochondrial superoxide using cyclic hydroxylamines. Free Radic. Res. 2011, 45, 417-430. [CrossRef]

29. De Bono, D.; Yang, W.D.; Symons, M.C. The effect of myoglobin on the stability of the hydroxyl-radical adducts of 5, 5 dimethyl1-pyrolline-N-oxide (DMPO), 3, 3, 5, 5 tetramethyl-1-pyrolline-N-oxide (TEMPO) and 1-alpha-phenyl-tert-butyl nitrone (PBN) in the presence of hydrogen peroxide. Free. Radic. Res. 1994, 20, 327-332. [CrossRef] [PubMed]

30. Migita, C.T.; Migita, K. Spin trapping of the nitrogen-centered radicals. Characterization of the DMPO/DEPMPO spin adducts. Chem. Lett. 2003, 32, 466-467. [CrossRef]

31. Neese, F. The ORCA program system. Wiley Interdiscip. Rev. Comput. Mol. Sci. 2012, 2, 73-78. [CrossRef]

32. Neese, F. Software update: The ORCA program system, version 4.0. Wiley Interdiscip. Rev. Comput. Mol. Sci. 2017, 8, 1-6. [CrossRef]

33. Neese, F.; Wennmohs, F.; Becker, U.; Riplinger, C. The ORCA quantum chemistry program package. J. Chem. Phys. 2020, 152, 224108. [CrossRef] [PubMed]

34. Adamo, C.; Barone, V. Toward reliable density functional methods without adjustable parameters: The PBE0 model. J. Chem. Phys. 1999, 110, 6158-6170. [CrossRef]

35. Weigend, F.; Ahlrichs, R. Balanced basis sets of split valence, triple zeta valence and quadruple zeta valence quality for $H$ to Rn: Design and assessment of accuracy. Phys. Chem. Chem. Phys. 2005, 7, 3297-3305. [CrossRef]

36. Grimme, S.; Antony, J.; Ehrlich, S.; Krieg, H. A consistent and accurate ab initio parametrization of density functional dispersion correction (DFT-D) for the 94elements H-Pu. J. Chem. Phys. 2010, 132, 154104. [CrossRef]

37. Marenich, A.V.; Cramer, C.J.; Truhlar, D.G. Universal Solvation Model Based on Solute Electron Density and on a Continuum Model of the Solvent Defined by the Bulk Dielectric Constant and Atomic Surface Tensions. J. Phys. Chem. B 2009, 113, 6378-6396. [CrossRef]

38. Avogadro: An Open-Source Molecular Builder and Visualization Tool, version 1.2; Available online: http:/ / avogadro.cc/ (accessed on 2 May 2021).

39. Hanwell, M.D.; Curtis, D.E.; Lonie, D.C.; Vandermeersch, T.; Zurek, E.; Hutchison, G.R. Avogadro: An advanced semantic chemical editor, visualization, and analysis platform. J. Cheminformatics 2012, 4, 17. [CrossRef]

40. Stoll, S.; Schweiger, A. EasySpin, a comprehensive software package for spectral simulation and analysis in ESR. J. Magn. Reson. 2006, 178, 42-55. [CrossRef]

41. Squella, J.A.; Bollo, S.; Núñez-Vergara, L.J. Recent Developments in the Electrochemistry of Some NitroCompounds of Biological Significance. Curr. Org. Chem. 2005, 9, 565-581. [CrossRef]

42. Grimshaw, J. Electrochemical Reactions and Mechanisms in Organic Chemistry; Grimshaw, J., Ed.; Elsevier: Amsterdam, The Netherlands, 2000; ISBN 0-444-72007-3.

43. Scholz, F.; Bond, A.M.; Compton, R.G.; Fiedler, D.A.; Inzelt, G.; Kahlert, H.; Komorsky-Lovric, ̌̌.; Lohse, H.; Lovric, M.; Marken, F.; et al. Electroanalytical Methods. Guide to Experiments and Application; Scholz, F., Ed.; Springer: Berlin, Germany, 2002; ISBN 978-3-642-02915-8.

44. Zuman, P.; Fijalek, Z.; Dumanovic, D.; Sužnjević, D. Polarographic and electrochemical studies of some aromatic and heterocyclic nitro compounds, part I: General mechanistic aspects. Electroanalysis 1992, 4, 783-794. [CrossRef]

45. Karakus, C.; Zuman, P.J.; Karakus, C.; Zuman, P. Polarographic and electrochemical studies of some aromatic and heterocyclic nitro compounds Part 9. Substitutent effects on protonation of the radical $\mathrm{ArNO}_{2} \mathrm{H}$ and its reactions with hydroxylamino and nitroso compounds in buffered mixtures of water and DMF. Electroanal. Chem. 1995, 396, 499-505. [CrossRef]

46. Rusakov, A.I.; Mendkovich, A.S.; Gultyay, V.P.; Orlov, V.Y. Structure and Reactivity of Organic Radical Anions; Mir: Moscow, Russia, 2005; ISBN 5-03-003772-1.

47. Michelson, A.M. Ions and Ion Pairs in Organic Reactions; Szwarc, M., Ed.; John Wiley and Sons: New York, NY, USA, 1972.

48. Cavalcanti, J.C.; Oliveira, N.V.; de Moura, M.A.B.; Fruttero, R.; Bertinaria, M.; Goulart, M.O. Evidence of self-protonation on the electrodic reduction mechanism of an anti-Helicobacter pylorimetronidazole isotere. Electroanal. Chem. 2004, 571, 177-182. [CrossRef] 
49. Maldonado, T.; Martínez-González, E.; Frontana, C. Intramolecular Hydrogen Bonding/Self protonation Processes Modulated by the Substituent Effect in Hydroxyl-substituted Naphthoquinones. Electroanalysis 2016, 28, 2827-2833. [CrossRef]

50. Jakubke, H.-D.; Eshkite, H. Amino Acids, Peptides, Proteins; Mitin, Y.V., Ed.; Mir: Moscow, Russia, 1985; ISBN 180-300-000-017-1.

51. Lopyrev, V.; Larina, L.; Rakhmatulina, T.; Shibanova, E.; Vakulskaia, T.; Voronkov, M. Dianion radicals of nitro derivatives of pyrazole, imidazole and 1,2,4-triazole. Fiz. Khimiya 1978, 242, 142-145. 